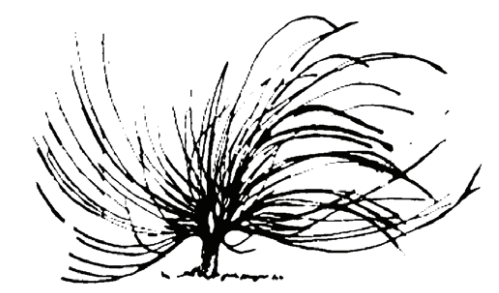

\title{
Globalización: no hay señal en la montaña
}

\author{
Óscar Ureña García ${ }^{1}$ \\ Universidad Federada San Judas Tadeo \\ Alajuela, Costa Rica \\ oscaru7@gmail.com
}

Resumen: La Globalización y el modelo de desarrollo neoliberal han empapado nuestra sociedad costarricense $\mathrm{y}$, con ello, se han abandonando aquellas políticas benefactoras de mitad del siglo $\mathrm{XX}$, que consistían en un estado más activo. Hoy el ser es gracias al tener. Y por más lejano o remoto que sea el lugar, ese mandamiento siempre está presente, como lo muestra esta crónica.

Palabras clave: Globalización. Empresarios. Neoliberalismo. Consumismo.

\begin{abstract}
:
The neoliberal development model and the globalization process have permed our Costa Rican society causing that welfare state policies from half of the XX century disappear. Nowadays, even in the farthest place being means having as it is shown in this chronicle.
\end{abstract}

Keywords: Globalization, young entrepreneurs, employers, neoliberalism, consumerism.

Recibido: 18 de febrero de 2011 - Aprobado: 30 de marzo de 2012

1 Bachiller en periodismo. Tesis en trámite para obtener el grado de Máster en Comunicación Política. Profesor Universitario y funcionario en la Universidad Federada San Judas Tadeo. 
B ienvenido a mi humilde finca, me dice Denis con una risa simpática y los cachetes colorados del frío, moviendo su gran cuerpo, alto, grueso y pesado. Mi mano helada se topa con unos gruesos dedos templados y su sonrisa choca contra mis muecas por el frío. Vamos a conversar adentro, me dice todo contento. Yo me muero de ganas de entrar entonces dejo las muecas para decirle que sí. Mientras, ahí afuera, la neblina de Poasito llega a tocarse con las nubes del cielo y la ciudad queda abajo junto con sus mortales. En este Olimpo, me parece que se vive como en un cielo. Aparte. Aislado.

Denis es un joven de 24 años que heredó un pequeña, muy pequeña, finca lechera de su abuelo que en la actualidad solo le sirve para subsistir. Él es el único nieto, de la única hija, que tuvo el difunto. Entonces, Denis vive con su mamá y trabaja allí casi completamente alejado de la ciudad. Algo extraño en estas épocas porque está aislado de la globalización: sin internet, porque el ICE no llega hasta allá. Sin cable, porque Amnet no ofrece su servicio hasta esas alturas. Tampoco hay señal de los celulares, porque el mío está muerto desde que traspasé las nubes para subir, colgadito, hasta allá arriba.

Tan solo hay que citar en un buscador de la web las palabras: “jóvenes con ideas" y aparecerán 45 millones 600 mil resultados en la búsqueda. La gran mayoría de ellas, para no decir que todos los primeros resultados, tratan sobre jóvenes empresarios: 10 ideas de negocios para jóvenes empresarios, asesoramiento para jóvenes emprendedores, 120 jóvenes son capacitados en sus ideas para negocios.

En este ahora, las ideas son para los negocios y lo demás no importa. Tengan, tengan; busquen cómo producir, sin importar cómo y de qué manera, dicta el mandamiento capitalista. La subsistencia no cuenta como empresario o emprendedor, el vivir lejos de la ciudad es pecado y no tener por tener, sino por necesidad, es algo completamente anticuado. Por eso a Denis, simplemente, no se lo puede catalogar como joven con ideas.

Entro a la casa por la cocina, y yo se lo agradezco porque me apartó del frío y me introdujo en una cocina templada por el calor de un fogón de leña y un olor a café y aguadulce.

Es una finca pequeña. Poco menos de media manzana, pero para Denis y su mamá es un paraíso. Algo bastante lógico, porque es su cielo, allá arribita de los mortales, sin necesidades banales, lo único que se puede hacer es mirar para arriba. Y, pues bueno, hablarle a Dios. Ese 
que está pegado en la pared, con un corazón ensangrentado, celestialmente cubierto por la gloria pintada por algún artista. Y la humilde casa que se me acerca y me adentra y el olor a desayuno que me despierta.

Me tuve que levantar muy temprano para subir y estar acá encima. El frío es tremendamente congelante en los pensamientos. Si clasificáramos anatómicamente este arriba, Denis no vive en las faldas, podríamos decir que vive en las tetas del Volcán Poás. Y a las 6 de la mañana son bastante frías. Algo poco placentero, anatómicamente hablando.

Después de notarlo, advierto que no hay cocina eléctrica, ni siquiera de gas. Tan solo una cocina de leña, una refri vieja y una mesa. La mamá me saluda muy efusivamente en su saludar y me toma del brazo de modo cariñoso, para luego darle vuelta a una tortilla con queso que está cocinándose en un comal. Denitos se levantó temprano para partir leña porque usted venía, me dice la mamá.

Denis estudió en una escuela de Poasito de Alajuela. Unos cuantos kilómetros más debajo de su finca. Como por el ombligo del Volcán, regresando a la anatomía de la montaña. Después de entrevistarme con él, pasaré a la escuela para darme cuenta que solo tiene 4 maestras y, cuando Denis estudió ahí, solo había dos. Una que daba clases a primer, segundo y tercer grado; la otra a cuarto, quinto y sexto. Algo muy alejado de lo que reza la globalización.

¿Pero qué es eso de la globalización?

Después de la tensión de la Guerra Fría, las cosas empezaron a ser un poquito diferentes en el mundo. Mijaíl Gorbachov tomó las riendas de la URSS y se topó con un agonizante imperio. El muro se cayó junto a la cortina de misterios. La filosofía de Marx y Lenin se quebrantaban ante el mundo y le daban un empujón a la otra filosofía económica: el neoliberalismo.

Entonces me sientan en una mesa pequeña, de esas mesas de los 60 con patas delgadas de hierro, flores y otros dibujos en la madera. Denis se sentó a la par mía y me preguntó si no importaba que la mamá de él nos sirviera mientras conversábamos. Es tan temprano y hace tanto frío que a mí no me importa cómo vaya a ser la entrevista. Algo disimulado, pongo a correr la grabadora del celular y, después de eso, me topo de frente con una tortilla con queso y un jarro metálico con café.

Tengo 7 vacas, me dice orgulloso. Entonces me comienza a explicar las labores qué hace. Se levanta a las 4 de la mañana y después de picar la leña y dejarle la carga diaria para que la mamá cocine, se va a 
ordeñar las vacas. Primero hay que bañarle las ubres, porque hay mucha cochinada. Luego agarro los tarros y se empieza a jalar. Vamos para que vea y ordeñe una. Ya venimos mami, le dice con su voz infantil.

El neoliberalismo es "un modelo de desarrollo", que propone la mínima intervención del Estado en materia económica y social para que el libre mercado capitalista sea quién dé el equilibrio institucional y el crecimiento económico de la nación. En otras palabras, quien tenga plata inviértala y muévala en el país, libre de intervenciones estatales. Algo bastante contradictorio con las políticas costarricenses de mitad de siglo XX. Aquellas hermosas reformas que tenían tendencia social, no tan económica y ayudaban a los pequeños productores como Denis.

La vaca se le tranquiliza después de pasarle la mano por el lomo. Denis se sienta, se para, se vuelve a tranquilizar. El cable, de esos para tender, le pasa por la mano para enlazar con cuidado las patas traseras del animal que me mira relajado. La manguera de agua inicia su reguero bañador de ubres, mientras Denis las restriega con la mano. La vaca se estremece un poco después del baño y se le mea encima de todo. Jueputa vaca, grita ofuscado, mientras yo me aguanto la risa bien adentrito de mi adentro.

De nuevo la baña, las gotas, en su gotear, saltan hacia abajo y ya se aparece el tarro metálico grande y las ubres reciben caricias, cariñosas y firmes hacia abajo para empezar a sacar poco a poco la leche, en chorros finos y ruidosos.

Después de recoger la leche, la empaco y me voy a venderla a Poasito, me dice mientras yo lo veo a los ojos y sus manos están toqueteando a la vaca. Yo le vendo a ciertas familias. No le vendo a cualquiera porque la gente es muy sinvergüenza. Además, no me da la producción de leche para venderle a tanta gente, me responde algo enojado cuando le pregunté si iba casa por casa vendiendo leche.

Mi sueño es tener más vacas, me dice. Yo, en mi pensar citadino, quizá contaminado por la globalización y el capitalismo, claramente comprendí que entre más número de ganado se tenga, más producción de leche, que a su vez lleva a más ventas y por último, más se gana y se puede alcanzar los sueños.

Unas vaquitas más me van ayudar a limpiar aquella parte de la finca. Es que como son tan pocas no pueden limpiar todo porque es muy grande, agrega y me bota completamente el pensamiento. 
Después de que cayera la polarización del mundo, salió la bendita palabrita a flote: globalización. Al principio se mostró como una combinación de culturas y conexiones entre ellas. Televisión, computadoras, internet y celulares para poder enlazarse. El mundo se conectaba entre sí y todos éramos todos, pero con el tiempo se pudo ver qué no era así. Es más bien un proceso económico, tecnológico, social e incluso geopolítico, en el que se unifican los mercados de todos los países, se incorporan los mismos patrones sociales de consumo y se amputa la pluralidad, eso sí, aceptando ciertas diferencias, como lo es Denis.

Mi mamá vive muy bien aquí. Ella no me preocupa tanto. La cocina de electricidad es muy peligrosa y es muy gastona. Además, con leña todo sabe más rico, me responde a la pregunta que si no desearía producir más para comprarle una cocina de electricidad a la mamá.

Esta casa la construyó mi abuelo. Es de madera, me dice cuando vamos entrando de nuevo a la casa, por el lado de la sala. Me doy cuenta que no hay un tele. Me hago el loco, porque de seguro en algún cuarto debe haber uno, pero la mamá le dice que le prenda el radio porque ya se le están pasando las noticias. Denis lo prende y le pregunto si tienen televisor y con una seriedad fría me dice que eso quita tiempo para trabajar.

En Costa Rica la explosión de la globalización y el consumo no tardó mucho en llegar. Ya en la década de los noventa tuvimos el primer boom de moles: Multiplaza, Mall San Pedro, Real Cariari, Mall Internacional, por mencionar algunos. Además del ingreso de más franquicias de comida chatarra como KFC y Taco Bell. Ya para la primera década del milenio teníamos moles en casi todas las provincias. Megamall en Cartago: Terramall; Megamall en Heredia: Paseo de las Flores. Moles en Liberia, Pérez Zeledón, Cuidad Neily y Guápiles. Cines en cada uno de ellos. La sociedad costarricense dejó de visitar lugares históricos y de recreación como los museos, zoológicos, teatros, para lanzarse a los centros comerciales y comprar a lo loco. Los jóvenes salen a consumir comida chatarra, comprarse ropa o videojuegos, para luego ver una película hollywoodense con desvalores norteamericanos.

Los fines de semana yo me quedo cuidando a mi mamá, me contesta Denis. A veces nos vamos a visitar a los vecinos, allá a Poasito o a veces ellos vienen acá. Yo tengo muchos amigos que vienen a jugar aquí. Son unos güilillas de la escuela. Hay uno, Juan Diego, siempre que viene a jugar y ordeñar las vacas me presta el celular para jugar, me dice emocionado con su voz infantil. 
Las telecomunicaciones fueron la piedra angular de la globalización y la sociedad de consumo. En nuestro país se dio el estallido de los celulares a principios del nuevo milenio con el ingreso de la red GSM, que trajo el ICE. Las líneas dejaron de ser extremadamente costosas, para estar al alcance de cualquiera. Con el paso del tiempo, también los celulares comenzaron a ser más baratos y hasta en los colegios y en las escuelas abundaban los jóvenes con aparatos.

Ahora estoy ahorrando para comprarme uno de esos. ¿Un qué? Le pregunto porque me distraje un momento viendo a ver si veía la ciudad entre un hueco de las nubes.

Un celular, me contesta pensativo. Tienen juegos y uno puede llamar a todo el mundo. Yo tengo varios a amigos que se hablan mandándose mensajes. Siempre he querido uno. ¿Usted tiene?, me pregunta.

Yo saco el mío, un 3G nuevo del ICE, lo reviso para ver si tengo algún mensaje, de paso para ver la hora y me doy cuenta que ni siquiera se tiene señal a estas alturas del mundo. Se lo doy para que lo vea. Lo revisa de arriba abajo, lo ve bien y me pregunta si puede jugar. Yo le digo que sí.

¿Y estos son muy caros? Yo voy a comprarme uno, ya me convencí. Uno aquí tan arriba ocupa algo para comunicarse con la gente, me menciona bastante seguro de lo que piensa. A mí me pareció mucho su idea, pero lo malo es que acá arriba, casi no hay señal. 